\title{
Interference of flavonoids with enzymatic assays for the determination of free fatty acid and triglyceride levels
}

\author{
Elise F. Hoek-van den Hil • Karsten Beekmann • \\ Jaap Keijer • Peter C. H. Hollman • \\ Ivonne M. C. M. Rietjens • Evert M. van Schothorst
}

Received: 5 September 2011 /Revised: 4 November 2011 / Accepted: 7 November 2011 /Published online: 26 November 2011

(C) The Author(s) 2011. This article is published with open access at Springerlink.com

\begin{abstract}
Flavonoids are bioactive food compounds with potential lipid-lowering effects. Commercially available enzymatic assays are widely used to determine free fatty acid (FFA) and triglyceride (TG) levels both in vivo in plasma or serum and in vitro in cell culture medium or cell lysate. However, we have observed that various flavonoids interfere with peroxidases used in these enzymatic assays, resulting in incorrect lower FFA and TG levels than actually present. Furthermore, addition of isorhamnetin or the major metabolite of the flavonoid quercetin in human and rat plasma, quercetin-3-Oglucuronide, to murine serum also resulted in a significant reduction of the detected TG levels, while a trend was seen for FFA levels. It is concluded that when applying these assays, vigilance is needed and alternative analytical methods, directly assessing FFA or TG levels, should be used for studying the biological effects of flavonoids on FFA and TG levels.
\end{abstract}

Keywords Free fatty acids · Triglycerides · Enzymatic assays $\cdot$ Flavonoids $\cdot$ Peroxidase

\footnotetext{
E. F. Hoek-van den Hil $(\bowtie) \cdot$ K. Beekmann • I. M. C. M. Rietjens Division of Toxicology, Wageningen University, Tuinlaan 5,

6703 HE Wageningen, The Netherlands

e-mail: elise.hoek@wur.nl
}

E. F. Hoek-van den Hil · J. Keijer • E. M. van Schothorst

Division of Human and Animal Physiology,

Wageningen University,

De Elst 1,

6708 WD Wageningen, The Netherlands

E. F. Hoek-van den Hil • P. C. H. Hollman

RIKILT-Institute of Food Safety,

Akkermaalsbos 2,

6708 WB Wageningen, The Netherlands

\section{Introduction}

Free fatty acid (FFA) and triglyceride (TG) plasma levels are important factors which can give an indication of the metabolic health status and are therefore generally used as markers of lipid metabolism. Commercially available enzymatic kits are widely used to determine FFA and TG levels. There are many advantages for the use of these assays, including small sample volume, no need for extraction, and high sensitivity [1]. Flavonoids are natural food compounds which are suggested to have beneficial lowering effects on lipid status [2]. Several studies investigated the effects of flavonoids on FFA and TG levels after dietary intervention or cell culture exposure and used these enzymatic kits to determine the lipid levels in serum cq. cell culture medium [3-9]. FFA and TG assays are based on enzymatic reactions. Independent of the supplier of the kits, peroxidase catalyzes the final quantitative conversion to the colored compound, which is subsequently measured by absorbance in both of these assays. Furthermore, also other frequently used enzymatic assays for the determination of, for example, cholesterol and glucose are based on peroxidase reactions.

In the FFA assay, FFAs are transformed into Acyl-coA, which is oxidized and generates hydrogen peroxide. In a quantitative oxidation reaction, hydrogen peroxide together with 3-methyl- $N$-ethyl- $N$-( $\beta$-hydroxyethyl) aniline and 4aminoantipyrine (4-AA) are converted into a blue purple product by peroxidase activity. Absorbance is used to quantify the FFA levels. In the TG assay, TGs are hydrolyzed with lipases generating glycerol, which is converted into glycerol-3-phosphate and oxidized generating hydrogen peroxide. Hydrogen peroxide and 4-AA are converted into quinoneimine catalyzed by peroxidase. 
Absorbance of quinoneimine is used to quantify the TG levels. It is clear that peroxidase has an important role in both assays because it catalyzes the final quantitative reaction. Importantly, flavonoids are known to be inhibitors of peroxidase activity [10-12]. Nevertheless, these assays are widely used in (nutritional) studies focusing on the effects of flavonoids. The inhibition of peroxidase by flavonoids may result in reduced peroxidase-mediated color formation, which will result in apparently lower FFA and TG levels than actually present. Therefore, the aim of the present study was to investigate whether at physiologically relevant concentrations flavonoids do indeed interfere with these widely applied peroxidase-based assays for the quantification of FFA and TG levels.

\section{Materials and methods}

\section{Sample preparation}

Cell culture medium samples were prepared in $1 \times$ DMEM high glucose without phenol red (Invitrogen, Breda, the Netherlands), with $10 \%$ fetal bovine serum charcoal/dextran treated (Thermo Scientific, Logan, Utah, USA), $2 \%$ penicillin-streptomycin (Invitrogen), and 1\% non-essential amino acids (Invitrogen). Medium was supplemented with $80 \mu \mathrm{M}$ linoleic acid-oleic acid-albumin (Sigma, Zwijndrecht, the Netherlands) and $20 \mathrm{mg} / \mathrm{dL}$ triglycerides standard. Quercetin, (+)-catechin (Sigma), naringenin, luteolin, kaempferol, and genistein (Extrasynthese, Lyon, France) were individually spiked to cell culture medium samples in different concentrations prior to measurements.

Serum samples obtained from Harlan Laboratories (Horst, the Netherlands) were pooled serum of C57BL/ 6JOlaHsd male mice. Quercetin, quercetin-3-O-glucuronide (Phytolab, Vestenbergsgreuth, Germany), and isorhamnetin (Extrasynthese) were spiked to the murine serum. All flavonoids were dissolved in DMSO, except quercetin-3-Oglucuronide which was dissolved in ethanol; for controls, only the solvent was added at equal volumes.

Free fatty acids assay

FFA kit reagents (Wako NEFA-HR(2) Kit, Sopachem BV, Ochten, the Netherlands) were used according to the manufacturer's protocol, with some small adaptations. The protocol mentions several usually present compounds in serum or plasma that may interfere with the assay; however, information on flavonoids or other bioactive food ingredients is not provided. Briefly, 5 or $15 \mu \mathrm{L}$ of sample plus $100 \mu \mathrm{L}$ of the first reagent were incubated for $10 \mathrm{~min}$ at $37^{\circ} \mathrm{C}$. Then, $50 \mu \mathrm{L}$ of the second reagent was added and incubated for another $10 \mathrm{~min}$ at $37^{\circ} \mathrm{C}$. Oleic acid (Wako
NEFA calibrator solution) was used for calibration curves. The absorbance was read at $550 \mathrm{~nm}$ using a Synergy HT plate reader (Biotek Instruments, Winooski, VT, USA).

Triglyceride assay

TG kit reagent (Triglycerides Liquicolor Kit, Human, Wiesbaden, Germany) was used according to the manufacturer's protocol. The protocol mentions several usually present compounds in serum or plasma that may interfere with the assay; however, information on flavonoids or other bioactive food ingredients is not provided. Briefly, $5 \mu \mathrm{L}$ of the sample plus $100 \mu \mathrm{L}$ reagent were incubated for $10 \mathrm{~min}$ at room temperature. Triglyceride standard from the kit was used for calibration curves. The absorbance was read at $500 \mathrm{~nm}$.

Statistical analysis

Statistical analysis was performed using one-way ANOVA followed by Dunnett's post hoc test. A $p$-value $<0.05$ was considered significant.

\section{Results and discussion}

Individual spiking of quercetin, kaempferol, and (+)catechin to the cell culture medium prior to measurements resulted in a significant reduction in the FFA levels detected (Fig. 1). The same flavonoids as well as luteolin caused also significant reductions in the TG levels detected. The apparent reduction in the levels of FFA and TG in these assays was already present at concentrations $(10-100 \mu \mathrm{M})$ which are generally used in in vitro studies, indicating that these peroxidase-based assays should be used with extreme caution under these circumstances. Different flavonoids are known to be able to inhibit peroxidase activity [10-12] and, thus, cause this unintentional reduction in the levels of FFA and TG detected by these assays.

Inhibition of myeloperoxidase activity is dependent on the presence of a hydroxyl group at the 3,5 and 4'positions in the structure of flavonoids and the $\mathrm{C}_{2}-\mathrm{C}_{3}$ double bond [12]. As a consequence, quercetin, kaempferol, and luteolin showed inhibition of myeloperoxidase in the following order: quercetin $>$ kaempferol $>$ luteolin [12]. This corresponds with our results, which also showed an identical interference capacity in the FFA and TG assays. However, genistein can also inhibit the activity of peroxidase [13], while we found no interference of genistein in both assays (Fig. 1).

In vivo, mainly metabolites of flavonoids are present in the circulation due to extensive intestinal and hepatic metabolism. Therefore, we analyzed the effect of individual spiking of quercetin, isorhamnetin, and the metabolite 
Fig. 1 Interference of different flavonoids on the FFA (a) and TG (b) levels in the cell culture medium measured by enzymatic assays. (+)-Catechin (filled square), quercetin (empty square), kaempferol (filled triangle), luteolin (empty triangle), genistein (filled circle), and naringenin (empty circle). Results are mean \pm SEM, $n=3$ for FFA and $n=4$ for TG Asterisk indicates a significant difference $(p<0.05)$ from the control $(0 \mu \mathrm{M})$. b Quercetin has already a significant effect at $10 \mu \mathrm{M}$ a

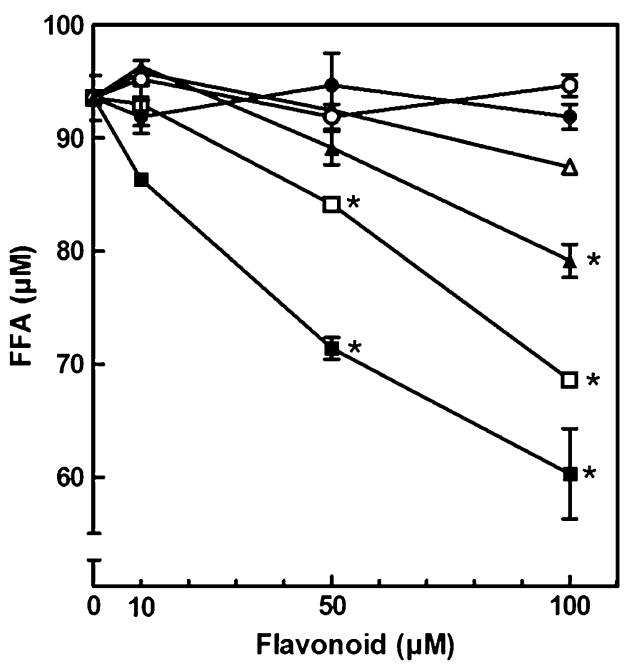

b

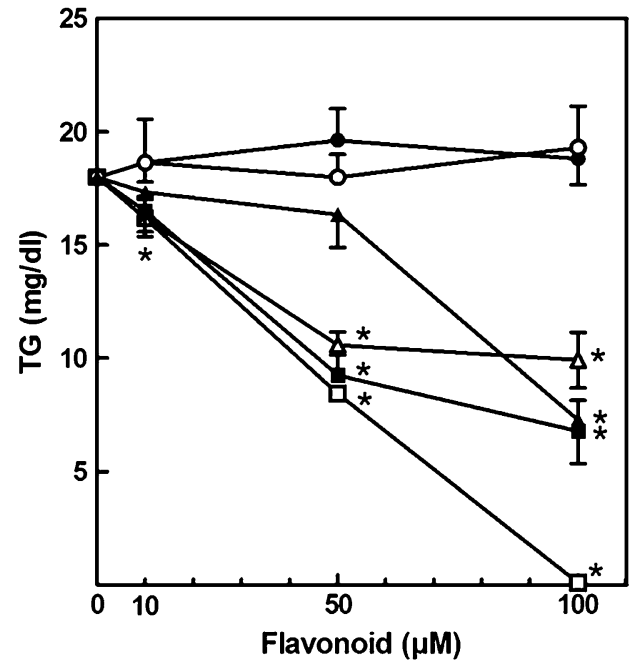

quercetin-3-O-glucuronide in murine serum. This also resulted in a significant reduction of the FFA and TG levels detected (Fig. 2). Quercetin-3-O-glucuronide is the major metabolite found in human and rat plasma [12, 14, 15]. It was previously shown that plasma concentrations of quercetin metabolites could inhibit myeloperoxidase [12]. This result corresponds with our finding that besides quercetin, also its metabolite, quercetin-3-O-glucuronide, interferes with the $\mathrm{TG}$ and FFA assays. Addition of quercetin-3-O-glucuronide resulted in a significant reduction in the detected TG levels, while at similar concentrations it did not have such a strong effect on the FFA assay. Furthermore, isorhamnetin seems to have a stronger effect on the FFA assay than on the TG assay at similar concentrations. Since the concentrations of quercetin-3-Oglucuronide resulting in these reductions of FFA and TG levels detected are in the range that can be observed in in vivo serum samples upon oral intake of quercetin [16], these observations show that when these enzymatic assays are used for in vivo studies, the results can also be unintentionally influenced.

There are several recent rodent nutritional studies with quercetin supplementation using these enzymatic assays to measure FFA and/or TG levels in serum or plasma [3-9]. The reported serum quercetin levels in these studies were between 10 and $45 \mu \mathrm{M}$. All studies reported decreased serum levels of FFA and/or TG after dietary quercetin supplementation, which could at least in part be due to the interference of quercetin with the FFA and TG assays, as shown in the present study. The peroxidase-based assays for FFA and TG have also been used in human flavonoid intervention studies, although most of them found no lipidlowering effects, which could be partly due to lower plasma flavonoid levels $[2,17]$. The present study showed a dosedependent interference of various flavonoids and of an important in vivo quercetin metabolite with peroxidasebased assays for the detection of FFA and TG levels. Therefore, the results of studies reporting a reduction in
Fig. 2 Interference of quercetin (empty square) and its major metabolite, quercetin-3-Oglucuronide (filled square), and isorhamnetin (circle) in murine serum on the FFA (a) and TG (b) levels measured by enzymatic assays. Results are mean \pm SEM, $n=8$. Asterisk indicates a significant difference $(p<0.05)$ from the control $(0 \mu \mathrm{M})$ a

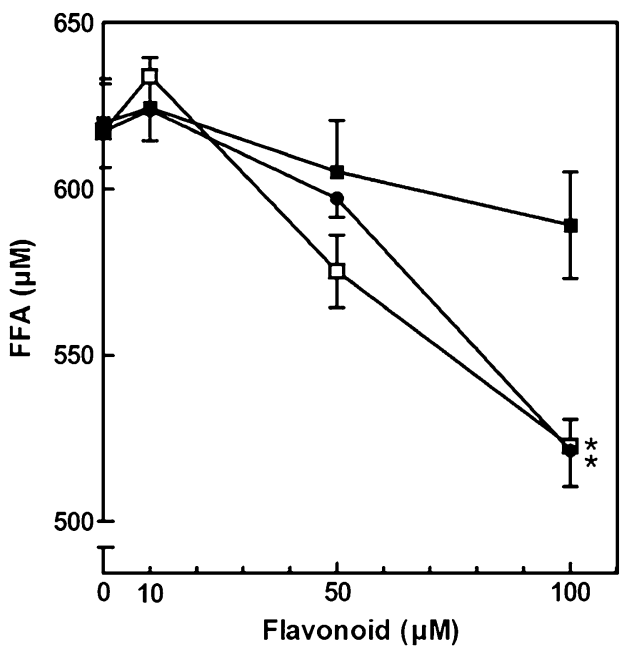

b

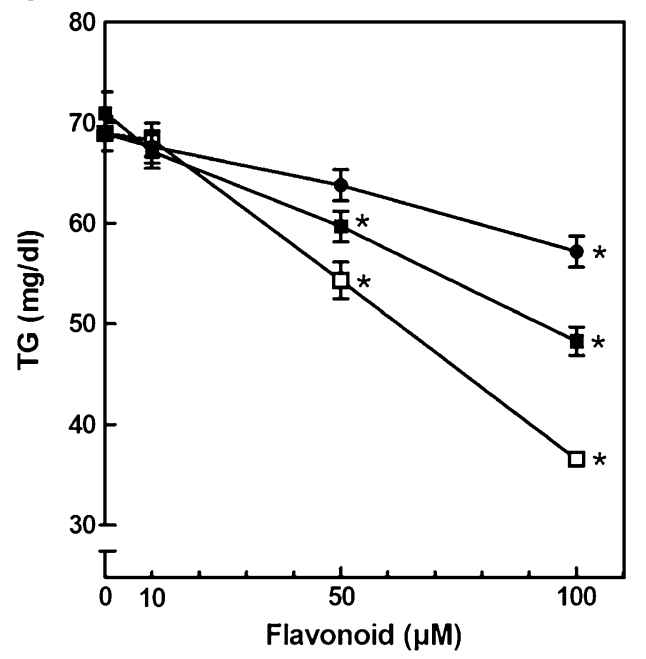


FFA and TG levels upon in vivo flavonoid supplementation should be interpreted with caution when these assays are used. Nevertheless, this does not exclude the biological effects on FFA and TG levels by flavonoids as effects are also perceived by the use of other analytical techniques $[18,19]$.

In conclusion, peroxidase-based enzymatic FFA and TG assays should be applied with caution in studies focusing on the effects of flavonoids. Interference of flavonoids and their metabolites with peroxidases used in these assays results in apparently lower levels of FFA and TG detected than actually present. Most likely, this will also hold for other enzymatic kits using peroxidase reactions, such as total cholesterol and glucose assays. Vigilance is needed and alternative methods including LC-MS, gas chromatography, or ${ }^{1} \mathrm{H}$ NMR should be used in studies focusing on the effects of flavonoids on lipid status.

Open Access This article is distributed under the terms of the Creative Commons Attribution Noncommercial License which permits any noncommercial use, distribution, and reproduction in any medium, provided the original author(s) and source are credited.

\section{References}

1. Shmeeda H, Even-Chen S, Honen R, Cohen R, Weintraub C, Barenholz Y (2003) Enzymatic assays for quality control and pharmacokinetics of liposome formulations: comparison with nonenzymatic conventional methodologies. Methods Enzymol 367:272-292

2. Chong MF, Macdonald R, Lovegrove JA (2010) Fruit polyphenols and CVD risk: a review of human intervention studies. $\mathrm{Br} \mathrm{J}$ Nutr 104(Suppl 3):S28-S39

3. An Y, Zhang Y, Li C, Qian Q, He W, Wang T (2011) Inhibitory effects of flavonoids from Abelmoschus manihot flowers on triglyceride accumulation in 3T3-L1 adipocytes. Fitoterapia 82(4):595-600

4. Kobayashi Y, Miyazawa M, Kamei A, Abe K, Kojima T (2010) Ameliorative effects of mulberry (Morus alba L.) leaves on hyperlipidemia in rats fed a high-fat diet: induction of fatty acid oxidation, inhibition of lipogenesis, and suppression of oxidative stress. Biosci Biotechnol Biochem 74(12):2385-2395

5. Kobori M, Masumoto S, Akimoto Y, Oike H (2011) Chronic dietary intake of quercetin alleviates hepatic fat accumulation associated with consumption of a western-style diet in C57/BL6J mice. Mol Nutr Food Res 55(4):530-540

6. Rivera L, Moron R, Sanchez M, Zarzuelo A, Galisteo M (2008) Quercetin ameliorates metabolic syndrome and improves the inflammatory status in obese Zucker rats. Obesity (Silver Spring) 16(9):2081-2087

7. Stewart L, Wang Z, Ribnicky D, Soileau J, Cefalu W, Gettys T (2009) Failure of dietary quercetin to alter the temporal progression of insulin resistance among tissues of C57BL/6 J mice during the development of diet-induced obesity. Diabetologia 52 (3):514-523

8. Wein S, Behm N, Petersen RK, Kristiansen K, Wolffram S (2010) Quercetin enhances adiponectin secretion by a PPAR-gamma independent mechanism. Eur J Pharm Sci 41(1):16-22

9. de Boer VC, van Schothorst EM, Dihal AA, van der Woude H, Arts IC, Rietjens IM, Hollman PC, Keijer J (2006) Chronic quercetin exposure affects fatty acid catabolism in rat lung. Cell Mol Life Sci 63(23):2847-2858

10. Divi RL, Doerge DR (1996) Inhibition of thyroid peroxidase by dietary flavonoids. Chem Res Toxicol 9(1):16-23

11. Pincemail J, Deby C, Thirion A, de Bruyn-Dister M, Goutier R (1988) Human myeloperoxidase activity is inhibited in vitro by quercetin. comparison with three related compounds. Experientia 44(5):450-453

12. Shiba Y, Kinoshita T, Chuman H, Taketani Y, Takeda E, Kato Y, Naito M, Kawabata K, Ishisaka A, Terao J, Kawai Y (2008) Flavonoids as substrates and inhibitors of myeloperoxidase: molecular actions of aglycone and metabolites. Chem Res Toxicol 21(8):1600-1609

13. Doerge DR, Chang HC (2002) Inactivation of thyroid peroxidase by soy isoflavones, in vitro and in vivo. J Chromatogr B Analyt Technol Biomed Life Sci 777(1-2):269-279

14. Day AJ, Mellon F, Barron D, Sarrazin G, Morgan MR, Williamson G (2001) Human metabolism of dietary flavonoids: identification of plasma metabolites of quercetin. Free Radic Res 35(6):941-952

15. Kawai Y, Saito S, Nishikawa T, Ishisaka A, Murota K, Terao J (2009) Different profiles of quercetin metabolites in rat plasma: comparison of two administration methods. Biosci Biotechnol Biochem 73(3):517-523

16. de Boer VC, Dihal AA, van der Woude H, Arts IC, Wolffram S, Alink GM, Rietjens IM, Keijer J, Hollman PC (2005) Tissue distribution of quercetin in rats and pigs. J Nutr 135(7):1718-1725

17. Cureton KJ, Tomporowski PD, Singhal A, Pasley JD, Bigelman KA, Lambourne K, Trilk JL, McCully KK, Arnaud MJ, Zhao Q (2009) Dietary quercetin supplementation is not ergogenic in untrained men. J Appl Physiol 107(4):1095-1104

18. Gnoni GV, Paglialonga G, Siculella L (2009) Quercetin inhibits fatty acid and triacylglycerol synthesis in rat-liver cells. Eur J Clin Invest 39(9):761-768

19. Radler U, Stangl H, Lechner S, Lienbacher G, Krepp R, Zeller E, Brachinger M, Eller-Berndl D, Fischer A, Anzur C, Schoerg G, Mascher D, Laschan C, Anderwald C, Lohninger A (2011) A combination of (omega-3) polyunsaturated fatty acids, polyphenols and L-carnitine reduces the plasma lipid levels and increases the expression of genes involved in fatty acid oxidation in human peripheral blood mononuclear cells and HepG2 cells. Ann Nutr Metab 58(2):133-140 